\title{
DESEMPENHO DE SEMENTES E PLANTAS DE FEIJOEIRO SOB EFEITO DO CONDICIONAMENTO OSMÓTICO E DA APLICAÇÃO DE ZINCO1
}

\author{
PERFORMANCE OF PLANTS AND SEEDS OF BEANS UNDER EFFECT OF \\ THE OSMOTIC CONDITIONING AND OF THE APLICATION OF ZINC
}

\author{
Cassio Carlos Ilgenfritz Sperotto ${ }^{2}$ Nilson Lemos de Menezes ${ }^{3}$ Lindolfo Storck $^{4}$
}

RESUMO

O feijão, principal fonte de proteína vegetal, é cultivado em todas as regiões do Brasil, geralmente com a utilização de sementes próprias e de má qualidade, justificando a utilização de tratamentos de sementes para melhorar sua qualidade. Este trabalho teve por objetivo avaliar os efeitos do condicionamento osmótico e da aplicação de zinco sobre o desempenho de sementes e plantas de feijoeiro (Phaseolus vulgaris L.). Instalaram-se ensaios com os cultivares Carioca, Macanudo, FT-120, em uтa primeira etapa no Laboratório de Análise de Sementes de Produção, do Departamento de Fitotecnia da UFSM e na área experimental da Fundação Estadual de Pesquisa Agropecuária do Rio Grande do Sul, em Júlio de Castilhos, RS. Os três cultivares foram submetidos aos seguintes tratamentos: Testemunha (sem tratamento pré-germinativo), PEG 6000 ( polietileno glicol 6000 - 15 bars por 16 horas), $\mathrm{PEG} 6000+\mathrm{ZnSO}_{4}$ (polietileno glicol 6000 , -15 bars por 16 horas $+5,5 \mathrm{~g} / \mathrm{kg}$ de sementes), $\mathrm{ZnSO}_{4}$ $(5,5 \mathrm{~g} / \mathrm{kg}$ de sementes). Após os tratamentos das sementes dos três cultivares, os mesmos foram avaliados quanto à germinação em laboratório e no campo. Avaliaram-se a emerêencia das plântulas, o desempenho das plantas e o rendimento de grãos. Concluiu-se que é possível a associação do PEG 6000 mais o zinco para o condicionamento osmótico e aplicação deste micronutriente nas sementes de feijão. $O$ condicionamento osmótico com o PEG 6000 isolado ou associado com o zinco aumenta a altura de inserção da primeira vagem, o número de vagens por planta e o número de sementes por vagem em plantas de feijoeiro.

Palavras-chave: feijão, micronutriente, semente.

\section{SUMMARY}

Beans represent the main source of vegetal protein, they are cultivated in all regions of Brazil, generally with the usage of own seeds and of bad quality, justifying the development

\begin{abstract}
of seed treatments to improve the quality of the seeds. The aim of this study was to evaluate the effects of the osmotic conditioning and the application of zinc on the performance of seeds and bean plants (Phaseolus vulgaris L.). Essays with the varieties Carioca, Macanudo, FT-120 were set up at the Seed Production Analysis Laboratory, of the Crop Production Department of UFSM, and at the experimental area of the Fundação Estadual de Pesquisa Agropecuária, in Júlio de Castilhos/RS. The three varieties were submitted to the following treatments: control (without pregerminative treatment); PEG 6000 (polyethylene glycol, -15 bars during 16 hours); PEG $6000+\mathrm{ZnSO}_{4}$ (polyethylene glycol 6000 -15 bars during 16 hours $+5.5 \mathrm{~g}$ of $\mathrm{ZnSO}_{4} / \mathrm{kg}$ of seeds) and $\mathrm{ZnSO}_{4}$ $(5.5 \mathrm{~g}$ of $\mathrm{ZnSO} 4 / \mathrm{kg}$ of seeds). After the application of treatments, seeds of the three varieties were evaluated concerning the germination and dash, at the laboratory. In the field, the number of growing plants was evaluated, also their performance and yield. It was concluded that it's possible the association of PEG 6000 (15 bars, 16 hours under $\left.25^{\circ} \mathrm{C}\right)$ plus Zinc $(5.5 \mathrm{~g} / \mathrm{kg}$ of seed) for the osmotic conditioning and the application of this micronutrient on the bean seeds. The osmotic conditioning with PEG 6000 isolated or associated with zinc increases the insertion height of the first pod, the number of pods per plant and the number of seeds per pod in bean plants.
\end{abstract}

Key words: beans, micronutrient, seeds.

\section{INTRODUÇÃO}

A etapa do estabelecimento das plantas em campo é de grande importância para qualquer cultura, podendo ser alterada por fatores como excesso ou deficiência de água, temperaturas extremas, estando também sujeitas ao ataque de insetos e microorganismos. Como alternativa de solução reco-

\footnotetext{
${ }^{1}$ Parte da dissertação apresentada pelo primeiro autor ao CPG em Agronomia / Universidade federal de Santa Maria (UFSM).

${ }^{2}$ Engenheiro Agrônomo, Mestre, CPG em Agronomia.

${ }^{3}$ Engenheiro Agrônomo, Doutor, Professor Adjunto, Departamento de Fitotecnia UFSM, 97105-900, Santa Maria, RS. E-mail: nmenezes@ccr.ufsm.br. Autor para correspondência.

${ }^{4}$ Engenheiro Agrônomo, Doutor, Professor Titular, Departamento de Fitotecnia UFSM, Bolsista CNPq.
} 
menda-se o uso de sementes de boa qualidade, associado a tratamentos pré-germinativos. Dentre os tratamentos que vem sendo aplicados com sucesso, em várias espécies, destacam-se o condicionamento osmótico e a aplicação de micronutrientes nas sementes. O condicionamento osmótico é uma técnica de embebição das sementes, em solução osmótica aquosa, que desencadeia os processos metabólicos da germinação, anterior à protusão da raiz primária. Tal procedimento possibilita o sincronismo na germinação, com reflexos no estande e até no rendimento (BEWLEY \& BLACK, 1978; KHAN et al., 1980/81; SAXENA \& SINGH, 1987). Atualmente, o polietileno glicol 6000 é o produto mais utilizado para esse tratamento por ser um polímero de elevado peso molecular, não eletrolítico e não tóxico às sementes (TALAVERA-WILLIAMS et al., 1991; VILLELA et al., 1991).

O tratamento das sementes com micronutrientes propicia uma aplicação uniforme, reduz custos e favorece sua absorção pela planta, influenciando, também, o rendimento, como foi constatado na cultura da soja (SANTOS et al., 1986) e na cultura do feijão (MELO, 1990). Dentre os micronutrientes de importância agronômica destaca-se o zinco, por participar dos processos metabólicos como componente de algumas enzimas, atuando como regulador de crescimento, influenciando a permeabilidade das membranas e estabilizando componentes celulares (THORNE, 1957; FERREIRA \& CRUZ, 1991).

O presente trabalho teve por objetivo avaliar o efeito do condicionamento osmótico com polietileno glicol 6000, sobre o desempenho das plantas de feijoeiro, bem como determinar a eficiência da aplicação do zinco na forma de tratamento de sementes e, ainda, avaliar a possibilidade de associação dos dois tratamentos para as sementes de feijão.

\section{MATERIAL E MÉTODOS}

O experimento foi dividido em duas etapas, sendo a primeira conduzida no Laboratório de Análise de Sementes de Produção (LASP) do Departamento de Fitotecnia da Universidade Federal de Santa Maria (UFSM). A segunda etapa foi realizada no Centro de Pesquisa em Sementes, da Fundação Estadual de Pesquisa Agropecuária do Estado do Rio Grande do Sul (FEPAGRO), em Júlio de CastilhosRS, no período de janeiro a abril de 1996.

Utilizaram-se três cultivares de feijão: $\mathrm{Ca}$ rioca, Macanudo e FT-120. Os tratamentos aplicados às sementes foram: testemunha (sem tratamento prégerminativo); PEG 6000 (-15 bars); PEG $6000+$ $\mathrm{ZnSO}_{4}(-15$ bars $+5,5 \mathrm{~g} / \mathrm{kg}$ de semente $) ; \mathrm{ZnSO}_{4}$ $(5,5 \mathrm{~g} / \mathrm{kg}$ de semente). Nos tratamentos em que foi utilizado o $\mathrm{ZnSO}_{4}$, as sementes foram colocadas em contato com o mesmo através da adição de $5 \mathrm{ml}$ de água destilada para cada $1000 \mathrm{~g}$ de semente; misturou-se e deixou-se secar à temperatura ambiente por alguns minutos. A solução para o condicionamento osmótico foi preparada mediante a dissolução de polietileno glicol 6000 (PEG 6000) em água. Utilizaram-se 367,66 gramas do produto por litro de água destilada, obtendo-se um potencial de -15bars (VILLELA et al., 1991).

Os tratamentos que envolveram o PEG 6000 foram aplicados nas sementes, que permaneceram sobre papel umedecido com a solução por 16 horas. Após este período, as sementes dos três cultivares apresentaram teores de água entre 24,6 e $29,5 \%$. Esses níveis de umidade foram considerados suficientes para a reorganização das membranas e a ativação do metabolismo celular, conforme a indicação de SIMON (1974). Para a execução do teste de germinação no LASP, seguiram-se as prescrições das Regras para a Análise de Sementes (BRASIL,1992), excetuando-se o número de sementes que foi de 200, distribuídas em quatro repetições iguais.

A instalação da etapa de campo foi efetuada no mês de janeiro, caracterizando a segunda safra de feijão no Rio Grande do Sul (safrinha). Logo após a aplicação dos tratamentos, as sementes foram semeadas, sem secagem. Para condução da cultura no campo, os tratos culturais foram feitos de acordo com as recomendações técnicas para a cultura. As avaliações efetuadas neste experimento foram a emergência das plântulas (cotilédones visíveis), alturas das plantas na floração, altura de inserção da primeira vagem, número de vagens por planta, número de sementes por vagem e rendimento de grãos $(\mathrm{kg} / \mathrm{ha})$.

O delineamento experimental para a etapa no LASP foi o inteiramente casualizado, com quatro repetições. Para o segundo experimento, na FEPAGRO, utilizou-se o delineamento em blocos ao acaso com parcelas subdivididas e quatro repetições. Nas parcelas principais foram casualizados os cultivares e nas subparcelas os tratamentos de sementes. Foi aplicada uma análise de variância e as médias comparadas pelo teste de Duncan, em nível de 5\% de probabilidade de erro.

\section{RESULTADOS E DISCUSSÃO}

O condicionamento osmótico, pelo uso do PEG6000, reduziu a germinação, em laboratório, das sementes dos três cultivares (tabela 1). Este tratamento pode apresentar efeitos variados entre espécies e lotes, nem sempre positivos, contrariando o esperado, pois, as sementes expostas a baixos poten- 
*Tratamentos com médias não seguidas pela mesma letra minúscula dentro de cada cultivar e maiúscula entre cultivares, diferem pelo teste de Duncan em nível de $5 \%$ de probabilidade de erro.

\begin{tabular}{|c|c|c|c|}
\hline \multirow[b]{2}{*}{ Tratamentos } & \multicolumn{3}{|c|}{ Cultivares } \\
\hline & Carioca & Macanudo & $\mathrm{FT}-120$ \\
\hline \multicolumn{4}{|c|}{ Em laboratórios } \\
\hline Testemunha & $92 \mathrm{a} *$ & $72 \mathrm{a}$ & $87^{\mathrm{a}}$ \\
\hline PEG 6000 & $43 c$ & $54 \mathrm{~b}$ & $68 \mathrm{c}$ \\
\hline Zinco (Zn) & $81 \mathrm{~b}$ & $73 a$ & $81 \mathrm{ab}$ \\
\hline PEG $6000+\mathrm{Zn}$ & $32 \mathrm{c}$ & $54 \mathrm{~b}$ & $72 \mathrm{bc}$ \\
\hline Média & $62 \mathrm{~B}$ & $63 \mathrm{~B}$ & $77 \mathrm{~A}$ \\
\hline \multicolumn{4}{|c|}{ A campo } \\
\hline Testemunha & $74,5 \mathrm{a}$ & $74,0 \mathrm{a}$ & $78,7 \mathrm{a}$ \\
\hline PEG 6000 & $29,0 \mathrm{~b}$ & $50,5 \mathrm{~b}$ & $53,0 \mathrm{~b}$ \\
\hline Zinco (Zn) & $70,3 \mathrm{a}$ & $59,8 \mathrm{~b}$ & $70,2 \mathrm{a}$ \\
\hline PEG $6000+Z n$ & $38,7 \mathrm{~b}$ & $59,8 \mathrm{~b}$ & $53,8 \mathrm{~b}$ \\
\hline Média & $53,1 \mathrm{C}$ & $61,0 \mathrm{~B}$ & 63,9 A \\
\hline
\end{tabular}

com KHAN et al. (1980/81) e BEWLEY \& BLACK (1985), a oxigenação é um dos fatores que influencia o condicionamento osmótico e sua deficiência pode causar deterioração das sementes e o desenvolvimento de fungos. Nos cultivares Macanudo e FT-120, o tratamento ou a aplicação apenas com zinco não diferiu da testemunha, indicando a possibilidade de aumentar a reserva deste micronutriente sem prejuízo à germinação, como já haviam observado SANTOS et al. (1986), em sementes de soja.

A emergência em campo, após os tratamentos com PEG 6000 (tabela 1), teve um comportamento semelhante ao da germinação em laboratório, provavelmente pelos mesmos motivos. Esses resultados discordam da maioria da literatura, no entanto, para que as comparações sejam completamente válidas é necessário que as metodologias também sejam semelhantes, fato não verificado. Os tratamentos apenas com zinco, nos cultivares Carioca e FT-120, não diferem da testemunha, ou seja, mantiveram o mesmo nível de emergência em campo, permitindo o acúmulo de zinco na semente e, provavelmente, a posterior translocação do micronutriente para a planta sem afetar o desempenho da ciais osmóticos, ao passarem para a condição de plena disponibilidade de água, podem ser prejudicadas quando comparadas a testemunha, como observou SHIOGA (1990). A germinação foi prejudicada pelo excesso de fungos e bactérias observados, que tiveram o seu desenvolvimento favorecido pelo condicionamento osmótico, sem oxigenação e sem tratamento fungicida. Esses controles não foram efetuados, porque considerou-se desnecessário tais procedimentos, quando em período de tempo inferior a 24 horas sobre papel. No entanto, de acordo semente, como havia observado MELO (1990).

Os resultados da avaliação de altura de plantas e inserção da primeira vagem, no campo, encontram-se na tabela 2. O cultivar Carioca foi superior aos demais, por ter obtido maior altura de plantas. $\mathrm{Na}$ comparação entre os tratamentos no cultivar carioca, verificou-se que aqueles contendo zinco produziram plantas de maior altura. $\mathrm{O}$ tratamento com PEG 6000 produziu plantas de mesma altura que o tratamento testemunha nos cultivares Carioca e Macanudo, porém menor no cultivar FT-

Tabela 2 - Altura de planta (AP) e altura de inserção da primeira vagem (AIV) em cm, de três cultivares de feijão, no campo, em função do condicionamento osmótico (PEG 6000) e do tratamento com zinco (Zn) nas sementes.

\begin{tabular}{|c|c|c|c|c|c|c|}
\hline \multirow[b]{2}{*}{ Tratamentos } & \multicolumn{2}{|c|}{ Carioca } & \multicolumn{2}{|c|}{ Macanudo } & \multicolumn{2}{|c|}{ FT-120 } \\
\hline & AP & AIV & AP & AIV & AP & AIV \\
\hline Testemunha & $57,85 \mathrm{bc}^{*}$ & $11,24 \mathrm{ab}$ & $32,83 \mathrm{a}$ & $10,85 a$ & $33,08 \mathrm{a}$ & $10,27 \mathrm{a}$ \\
\hline PEG 6000 & $55,47 \mathrm{c}$ & $11,58 \mathrm{a}$ & $35,35 \mathrm{a}$ & $10,73 a$ & $28,71 b$ & $11,05 \mathrm{a}$ \\
\hline Zinco (Zn) & $62,67 \mathrm{a}$ & $9,36 \mathrm{c}$ & $32,52 \mathrm{a}$ & $11,46 a$ & $32,51 \mathrm{ab}$ & $10,20 \mathrm{a}$ \\
\hline PEG $6000+Z n$ & $60,44 \mathrm{ab}$ & $10,01 b c$ & $32,10 \mathrm{a}$ & $11,35 \mathrm{a}$ & $33,53 \mathrm{a}$ & $10,22 \mathrm{a}$ \\
\hline Média & $59,10 \mathrm{~A}$ & $10,54 \mathrm{~B}$ & $33,21 \mathrm{~B}$ & $11,08 \mathrm{~A}$ & $31,95 \mathrm{C}$ & $10,43 \mathrm{~B}$ \\
\hline
\end{tabular}

*Tratamentos com médias não seguidas pela mesma letra minúscula dentro de cada cultivar e maiúscula entre cultivares, diferem pelo teste de Duncan em nível de $5 \%$ de probabilidade de erro. 
120. Na avaliação da altura de inserção da primeira vagem, não houve diferenças entre os tratamentos nos cultivares Macanudo e FT-120. Apenas para o cultivar Carioca, o tratamento com PEG 6000 foi superior ao tratamento com zinco e zinco mais PEG6000, sem diferir da testemunha. Assim, o zinco associado ou não com PEG6000 reduz a altura de inserção da primeira vagem. A altura de planta e de inserção de primeira vagem são parâmetros importantes na cultura do feijoeiro, porque afetam a colheita mecânica e a sanidade das sementes. Os resultados, no entanto, não demonstram diferenças suficientes entre os tratamentos, e são dependentes das características varietais.

O número de vagens por planta, dos três cultivares, está apresentado na tabela 3 , onde verifica-se um comportamento distinto entre os tratamentos em dois cultivares. Nestes, os tratamentos com PEG 6000 e/ou zinco foram superiores no cultivar FT-120 e não diferiu da testemunha no cultivar Carioca, indicando a possibilidade do uso do condicionamento osmótico ou com zinco nas sementes de feijão, para melhorar o número de vagens por planta, principalmente em situações nas quais, devido à qualidade média das sementes, espera-se dificuldades no campo.

$\mathrm{Na}$ tabela 3, observaram-se os resultados relativos ao número de sementes por vagem, onde está demonstrada a superioridade do cultivar Macanudo sobre os demais. Todos os tratamentos aplicados às sementes propiciaram aumento no número de sementes por vagem em relação à testemunha. Esses

Tabela 3 - Número de vagens por planta e número de sementes por vagem, na maturação de três cultivares de feijão em função do condicionamento osmótico (PEG 6000) e do tratamento com zinco $(\mathrm{Zn})$ nas sementes.

\begin{tabular}{lcccc}
\hline & \multicolumn{3}{c}{ Número de vagem/planta } & $\begin{array}{c}\text { N semente } \\
\text { /vagem }\end{array}$ \\
& & & \\
\cline { 2 - 4 } Tratamentos & Carioca & Macanudo & FT -120 & ------- \\
& & & & \\
\hline & & & & \\
Testemunha & $11,17 \mathrm{~b} *$ & $13,00 \mathrm{a}$ & $9,37 \mathrm{~b}$ & $5,55 \mathrm{~b}$ \\
PEG 6000 & $15,91 \mathrm{a}$ & $13,27 \mathrm{a}$ & $11,76 \mathrm{a}$ & $5,94 \mathrm{a}$ \\
Zinco (Zn) & $10,53 \mathrm{~b}$ & $14,12 \mathrm{a}$ & $10,36 \mathrm{ab}$ & $5,84 \mathrm{a}$ \\
PEG 6000 + Zn & $10,87 \mathrm{~b}$ & $13,18 \mathrm{a}$ & $12,11 \mathrm{a}$ & $5,85 \mathrm{a}$ \\
Média & $12,12 \mathrm{~B}$ & $13,39 \mathrm{~A}$ & $10,90 \mathrm{C}$ & \\
N semente/vagem & $5,67 \mathrm{~B} *$ & $6,08 \mathrm{~A}$ & $5,64 \mathrm{~B}$ & \\
& & & & \\
\hline
\end{tabular}

*Tratamentos com médias não seguidas pela mesma letra minúscula dentro de cada cultivar e maiúscula entre cultivares, diferem pelo teste de Duncan em nível de 5\% de probabilidade de erro. resultados demonstram que os efeitos dos tratamentos podem ser observados além da fase de implantação da cultura, como um importante componente de rendimento.

Os tratamentos não demonstraram efeitos suficientemente claros sobre o rendimento dos três cultivares de feijão (tabela 4), de modo a permitir conclusões sobre a sua aplicação. Houve comportamento distinto nos três cultivares estudados. Embora exista boa probabilidade de que a qualidade das sementes exerça influência positiva sobre o rendimento, quando o órgão avaliado seja de origem vegetativa, os resultados nem sempre são muito

Tabela 4 - Rendimento $(\mathrm{kg} / \mathrm{ha})$ de três cultivares de feijão, em função dos tratamentos de condicionamento osmótico ( PEG 6000) e zinco ( $\mathrm{Zn}$ ) nas sementes.

\begin{tabular}{llll}
\hline Tratamentos & Carioca & Macanudo & FT -120 \\
& & & \\
& & & \\
Testemunha & $613,25 \mathrm{a}^{*}$ & $709,50 \mathrm{a}$ & $612,25 \mathrm{ab}$ \\
PEG 6000 & $568,00 \mathrm{a}$ & $545,25 \mathrm{bc}$ & $476,75 \mathrm{~b}$ \\
Zinco $(\mathrm{Zn})$ & $506,00 \mathrm{a}$ & $675,75 \mathrm{ab}$ & $627,25 \mathrm{a}$ \\
PEG 6000 + Zn & $645,00 \mathrm{a}$ & $499,00 \mathrm{c}$ & $569,50 \mathrm{ab}$ \\
Média & $583,06 \mathrm{~B}$ & $607,37 \mathrm{~A}$ & $571,43 \mathrm{C}$ \\
& & & \\
\hline
\end{tabular}

*Tratamentos com médias não seguidas pela mesma letra minúscula dentro de cada cultivar e maiúscula entre cultivares, diferem pelo teste de Duncan em nível de $5 \%$ de probabilidade de erro.

claros, conforme alertou CARVALHO (1986) quando se exploram sementes. Cabe ressaltar, porém, que os tratamentos com PEG 6000 que prejudicaram a germinação e a emergência em campo estabeleceram plantas vigorosas, que compensaram os prejuízos e não diferiram em rendimento.

O cultivar Macanudo apresentou o maior rendimento $(607,2 \mathrm{~kg} / \mathrm{ha})$, superando os demais, confirmando o esperado, por ter apresentado maior número de vagens por planta e maior número de sementes por vagem. O rendimento obtido alcançou valores de acordo com a safra de produção (safrinha), pois o rendimento médio nacional foi de aproximadamente $570 \mathrm{~kg} / \mathrm{ha}$ no período 1990-1994 (YOKOYAMA et al., 1996).

Os efeitos positivos do condicionamento osmótico sobre os componentes do rendimento, na produção de sementes, são pouco relatados na literatura sobre o assunto. Tal fato foi observado no presente trabalho, que confirma 
os benefícios desse tratamento nas grandes culturas, embora, não se tenham observado efeitos positivos na qualidade fisiológica das sementes. Esses resultados, porém, indicam a necessidade de maiores estudos sobre a metodologia e sua operacionalização para lotes das sementes das espécies de maior interesse agrícola.

\section{CONCLUSÕES}

O condicionamento osmótico e a aplicação de zinco podem ser efetuados no mesmo momento, em sementes de feijão, sob as condições de 15 bars de potencial osmótico, por 16 horas a $25^{\circ} \mathrm{C}$, mais a dosagem de $5,5 \mathrm{~g}$ de $\mathrm{ZnSO}_{4} / \mathrm{kg}$ de semente; o condicionamento osmótico com o Polietileno Glicol ou a associação PEG 6000 com zinco aplicados às sementes aumenta o número de vagens por planta e o número de sementes por vagem em plantas de feijoeiro.

\section{REFERÊNCIAS BIBLIOGRÁFICAS}

BEWLEY, J.D., BLACK, M. Physiology and biochemistry of seeds in relation to germination. Berlin: Springer - verlag, 1978. 2 v.

BEWLEY, J.D., BLACK, M. Seeds physiology of development and germination. New York: Plenum, 1985.367 p.

BRASIL. Ministério da Agricultura e Reforma Agrária. Normas para a produção de sementes fiscalizadas CESM/RS. Porto Alegre: DFARA/RS, 1992. 73 p.

CARVALHO, N.M. Semana de atualização em produção de sementes, s.1986. Piracicaba: Fundação Cargill, 1986. Vigor de sementes. P. 207-223.

FERREIRA, M.E., CRUZ, M.C.P. Micronutrientes na Agricultura. Piracicaba: POTAFÓS/CNPq, 1991. 734 p.
KHAN, A.A., PECK, N.H., SOMIMY, C. Seed osmoconditioning: phisiological and biochemical changes Israel Journal of Botany, Jerusalém, v. 29, p. 133-144, 1980/81.

MELO, E.F.R.Q. Respostas da cultura do feijão (Phaseolus vulgaris $L$ ) a níveis de zinco nas formas inorgânicas e orgânicas em casa de vegetação e no campo. Curitiba: UFPAR, 1990, 125 p. Dissertação (Mestrado em ciência do solo) - Curso de de pós-graduação em ciência do solo, Universidade Federal do Paraná, 1990.

SANTOS, O.S., ESTEFANEL, V., CAMARGO, R.P. Efeito da aplicação do molibdênio e do zinco em sementes de soja sobre o teor desses nutrientes. In: UFSM. Soja: relatório de pesquisa do centro de ciências rurais. Santa Maria, 1986. p. $39-44$

SAXENA, O.P., SINGH, G. Osmotic priming studies in some vegetable seeds. Acta Horticulturae, The Hague, v. 215, p. $201-207,1987$.

SHIOGA, P.S. Controle da hidratação e desempenho das sementes de feijão (Phaseolus vulgaris L.). Piracicaba: ESALQ, 1990. 106p. Tese (Mestrado em Agronomia) - Escola Superior de Agricultura Luiz de Queiroz, Universidade de São Paulo, 1990

SIMON, E.W. Phospholipids and plant membrane permeability. New phytologist, Cambridge, v. 73, p. 377-420, 1974.

TALAVERA-WILLIAMS, C.G., PACKED, A.W., BUJALSKI, W. et al. A feasibiliti study of the bulk priming and drying of tomato seeds. Trans Ind Chem Ecol, [S.1.], v. 69, p. 134 144, 1991.

THORNE, W. Zinc deficiency and its control. Advances in Agronomy, New York, v. 9, p. 31-61, 1957.

VILLELA, F.A., DONI FILHO, L., SEQUEIRA, E.L. Tabela de potencial osmótico em função da concentração de polietileno glicol 6000 e da temperatura. Pesquisa Agropecuária Brasileira, Brasília, v. 26, n. 11-12, p. 1957-1968, 1991.

YOKOYAMA, L.P., BANNO,K., KLUTHCOUSKI, J. Aspectos socioeconomicos da cultura In: ARAUJO, R.S., RAVA, C.A., STONE, L.S., et al. Cultura do feijoeiro comum no Brasil. Piracicaba: POTAFOS, 1996. p. 1-22.

Ciência Rural, v. 29, n. 2, 1999. 